Supporting Information

\title{
Liberating Active Metals from Reducible Oxide Encapsulation for Superior Hydrogenation Catalysis
}

Qijun Pei, ${ }^{\dagger,+}$ Teng He, ${ }^{* \dagger}$ Y Yang Yu, ${ }^{\dagger, *}$ Zijun Jing, ${ }^{\dagger,+}$ Jianping Guo, ${ }^{\dagger}$ Lin Liu, ${ }^{\dagger}$ Zhitao Xiong $^{\dagger}$ and Ping Chen $*, \dagger, \S$,

†Dalian National Laboratory for Clean Energy, Dalian Institute of Chemical Physics, Chinese Academy of Sciences, Dalian 116023, China.

$\$$ University of Chinese Academy of Sciences, Beijing 100049, China.

${ }^{\S}$ State Key Laboratory of Catalysis, Dalian Institute of Chemical Physics, Chinese Academy of Sciences, Dalian 116023, China.

"Collaborative Innovation Centre of Chemistry for Energy Materials (iChEM·2011), Xiamen University, Fujian 361005, China.

Corresponding authors'E-mails: heteng@dicp.ac.cn (T.H.); pchen@dicp.ac.cn (P.C.) 
Table S1. The proposed reactions for $\mathrm{TiO}_{2}$ with sodium and lithium salts.

\begin{tabular}{|c|c|}
\hline \multicolumn{2}{|l|}{ Na salts } \\
\hline $2 \mathrm{NaOH}+\mathrm{TiO}_{2}=\mathrm{Na}_{2} \mathrm{TiO}_{3}+\mathrm{H}_{2} \mathrm{O}$ & R S 1 \\
\hline $\mathrm{Na}_{2} \mathrm{CO}_{3}+\mathrm{TiO}_{2}=\mathrm{Na}_{2} \mathrm{TiO}_{3}+\mathrm{CO}_{2}$ & R S2 \\
\hline $2 \mathrm{NaNO}_{3}+\mathrm{TiO}_{2}+\mathrm{H}_{2}=\mathrm{Na}_{2} \mathrm{TiO}_{3}+2 \mathrm{NO}_{2}+\mathrm{H}_{2} \mathrm{O}$ & R S3 \\
\hline $2 \mathrm{NaCl}+\mathrm{TiO}_{2}+\mathrm{H}_{2} \mathrm{O}=\mathrm{Na}_{2} \mathrm{TiO}_{3}+2 \mathrm{HCl}$ & R S4 \\
\hline \multicolumn{2}{|l|}{ Li salts } \\
\hline $2 \mathrm{LiOH}+\mathrm{TiO}_{2}=\mathrm{Li}_{2} \mathrm{TiO}_{3}+\mathrm{H}_{2} \mathrm{O}$ & R S5 \\
\hline $\mathrm{Li}_{2} \mathrm{CO}_{3}+\mathrm{TiO}_{2}=\mathrm{Li}_{2} \mathrm{TiO}_{3}+\mathrm{CO}_{2}$ & R S6 \\
\hline $2 \mathrm{LiNO}_{3}+\mathrm{TiO}_{2}+\mathrm{H}_{2}=\mathrm{Li}_{2} \mathrm{TiO}_{3}+2 \mathrm{NO}_{2}+\mathrm{H}_{2} \mathrm{O}$ & R S7 \\
\hline $2 \mathrm{LiCl}+\mathrm{TiO}_{2}+\mathrm{H}_{2} \mathrm{O}=\mathrm{Li}_{2} \mathrm{TiO}_{3}+2 \mathrm{HCl}$ & R S8 \\
\hline
\end{tabular}




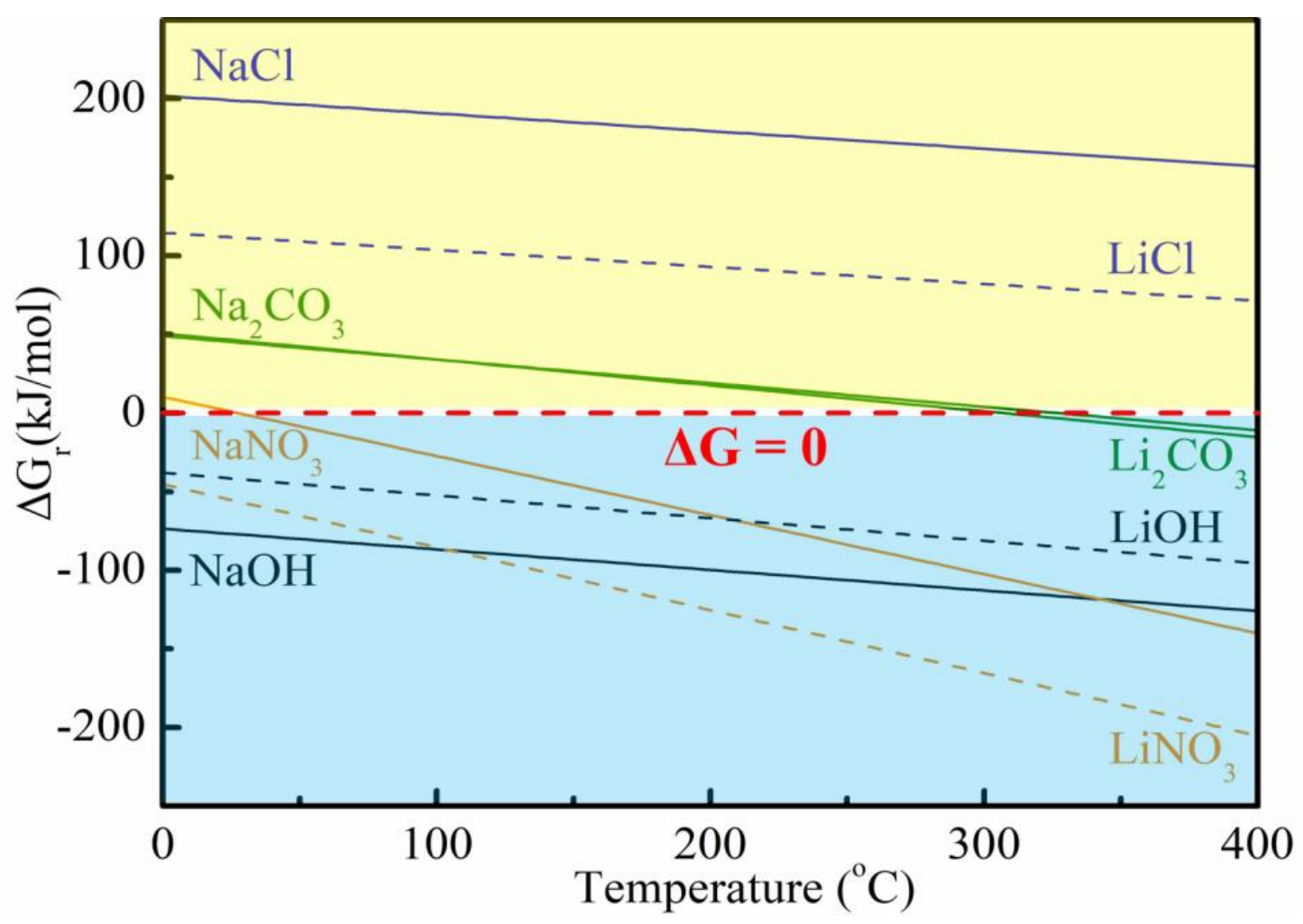

Figure S1. Thermodynamic analyses of the reactions between $\mathrm{TiO}_{2}$ and sodium or lithium salts to form corresponding titanates. 


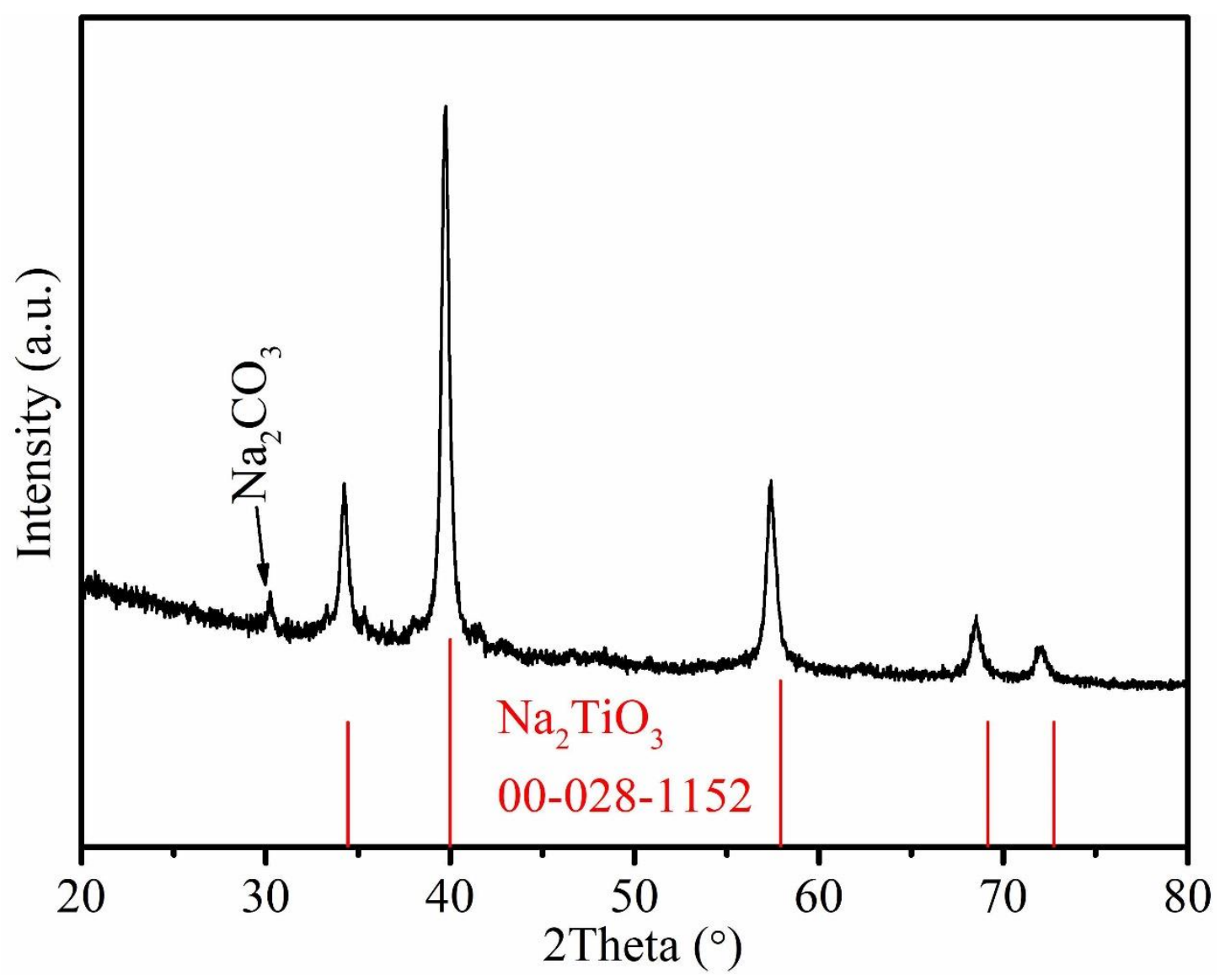

Figure S2. XRD pattern of the sample from the reaction of $\mathrm{NaOH}$ and $\mathrm{TiO}_{2}$ in molar ratio 3:1. $\mathrm{Na}_{2} \mathrm{CO}_{3}$ is the contamination of $\mathrm{NaOH}$ by $\mathrm{CO}_{2}$ from the air. 


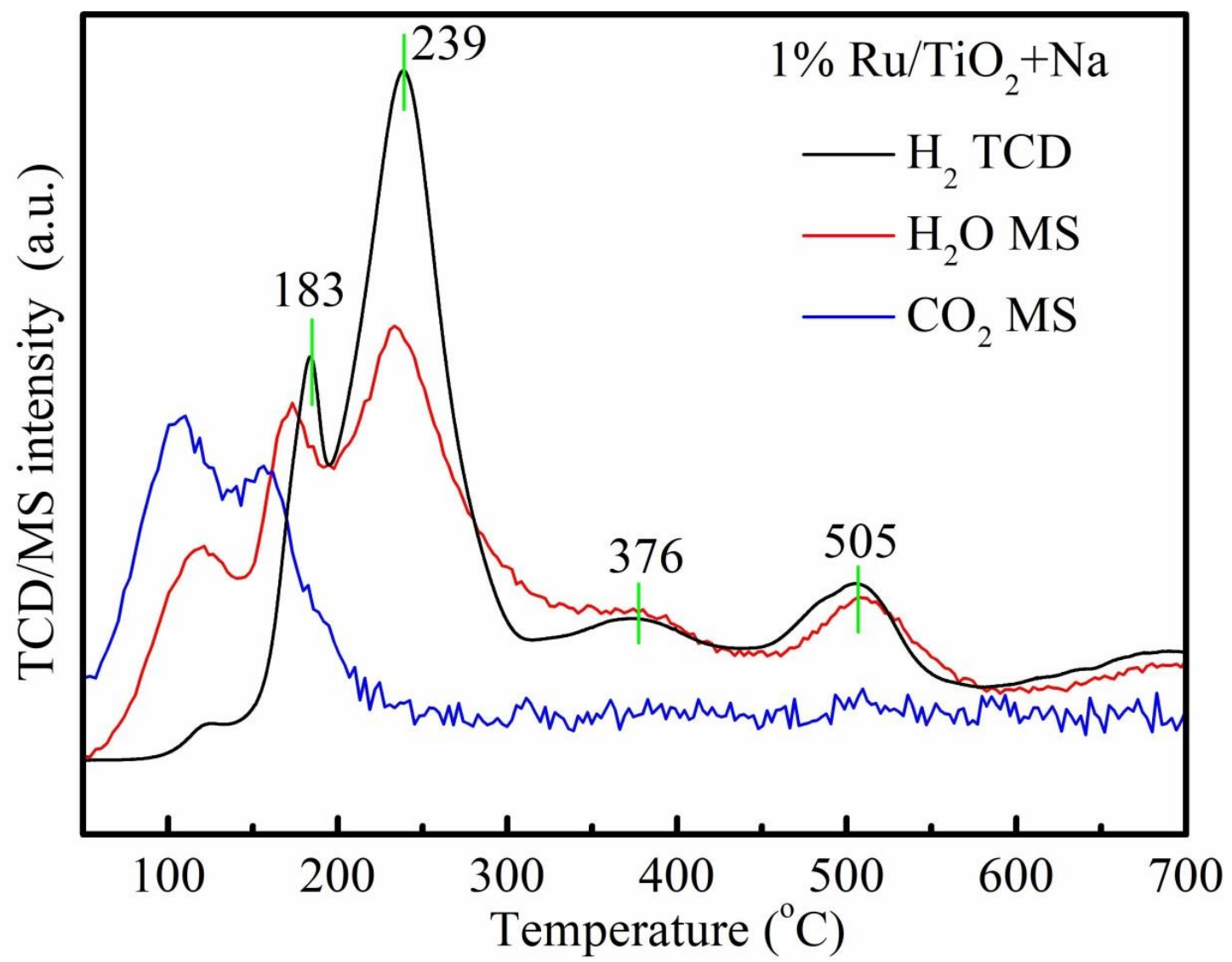

Figure $\mathrm{S} 3$. The combined $\mathrm{H}_{2}-\mathrm{TPR}$ profiles from TCD signal and MS signals of $\mathrm{m} / \mathrm{z}=$ $18\left(\mathrm{H}_{2} \mathrm{O}\right), \mathrm{m} / \mathrm{z}=44\left(\mathrm{CO}_{2}\right)$. 


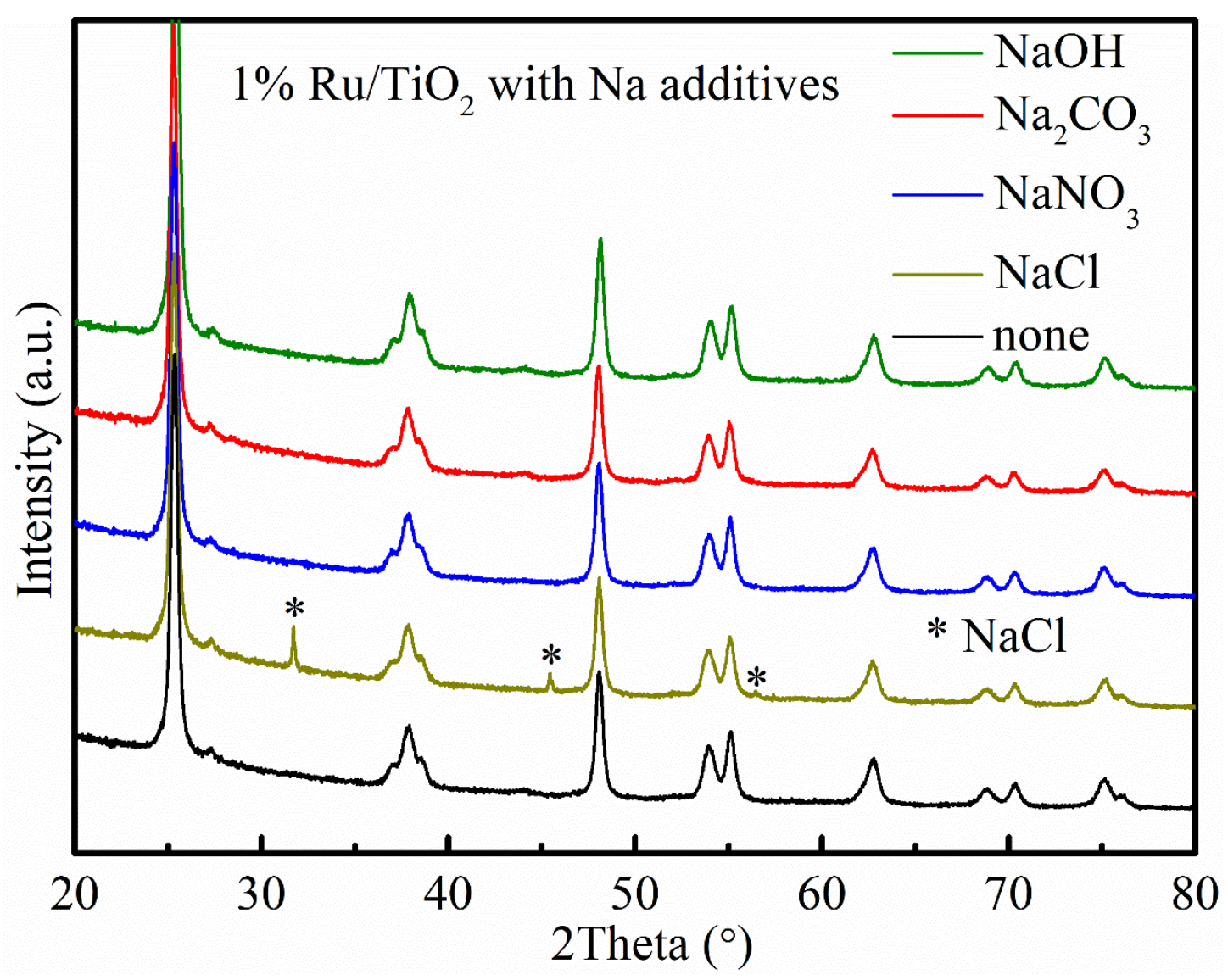

Figure $\mathrm{S} 4$. XRD patterns of $\mathrm{H}_{2}$ reduced $1 \% \mathrm{Ru} / \mathrm{TiO}_{2}$ and $1 \% \mathrm{Ru} / \mathrm{TiO}_{2}$ modified by different $\mathrm{Na}$ additives. 

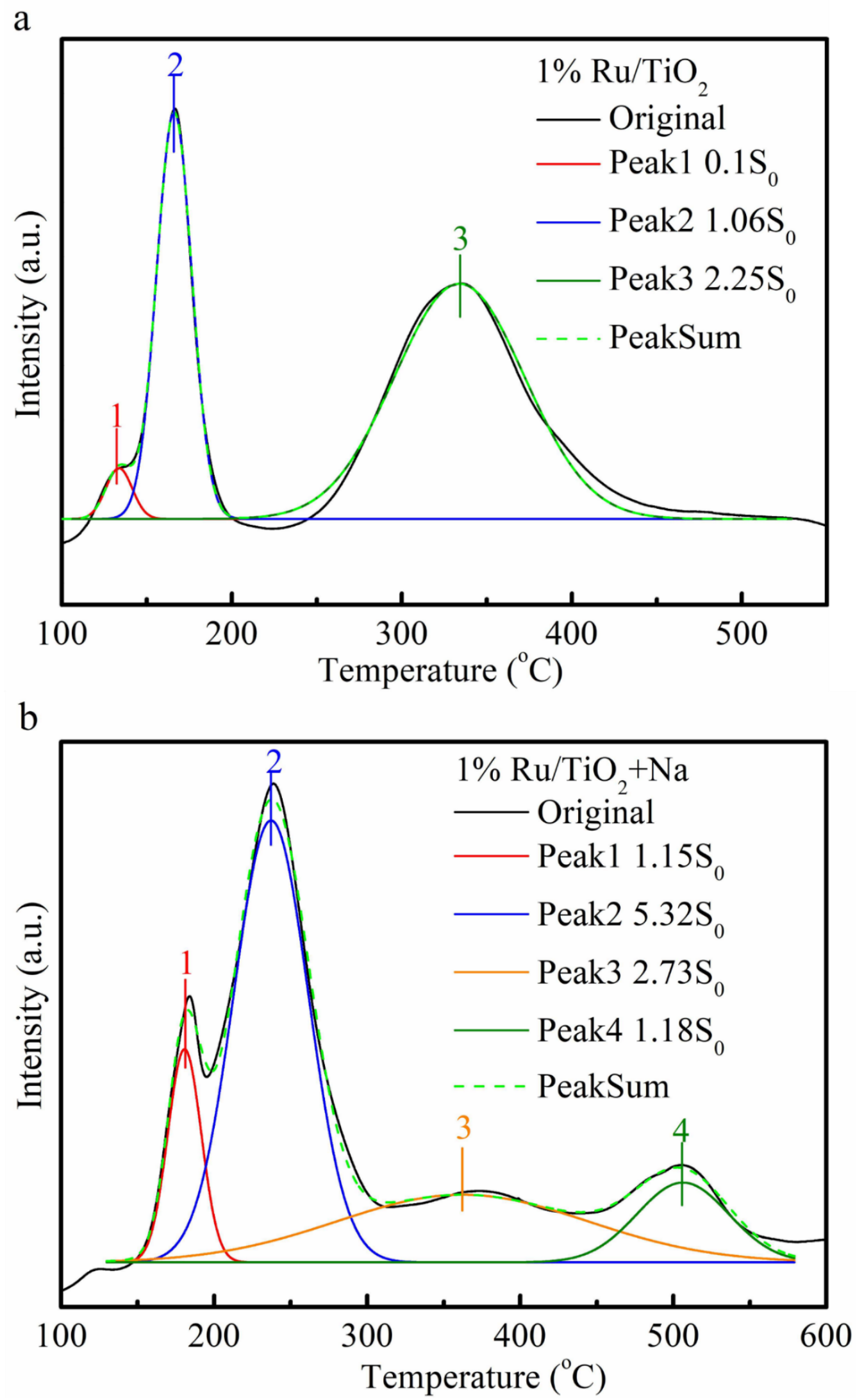

Figure $\mathrm{S} 5 . \mathrm{H}_{2}-\mathrm{TPR}$ profiles of (a) $1 \% \mathrm{Ru} / \mathrm{TiO}_{2}$ and (b) $1 \% \mathrm{Ru} / \mathrm{TiO}_{2}+\mathrm{Na}$. $\mathrm{S}_{0}$ means the theoretical area of hydrogen consumption by ruthenium oxide in the catalysts. 


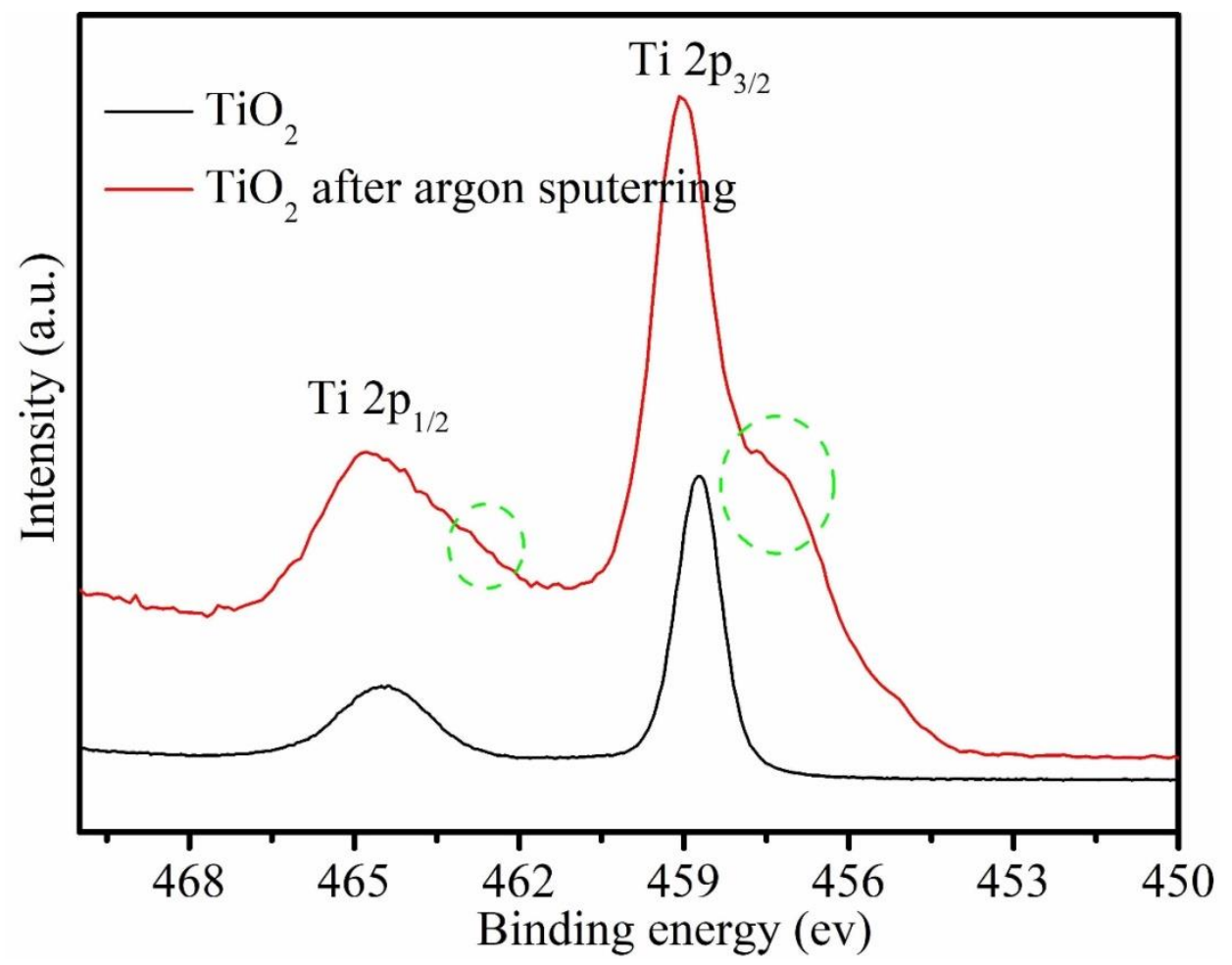

Figure S6. XPS spectra for $\mathrm{Ti}$ of $\mathrm{TiO}_{2}$ with and without argon sputtering. 


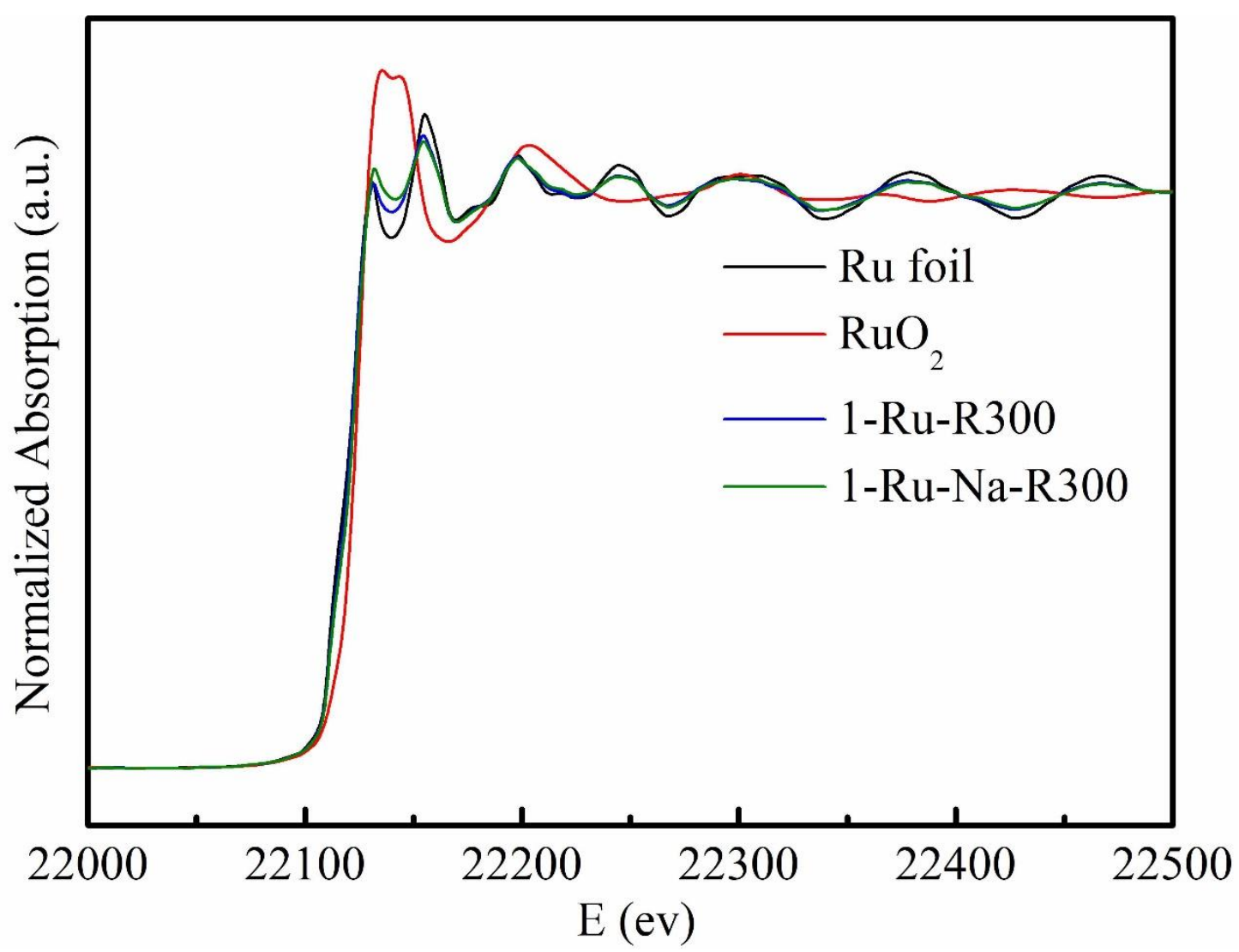

Figure S7. The Ru K-edge XANES spectra of 1-Ru-R300 and 1-Ru-Na-R300. 


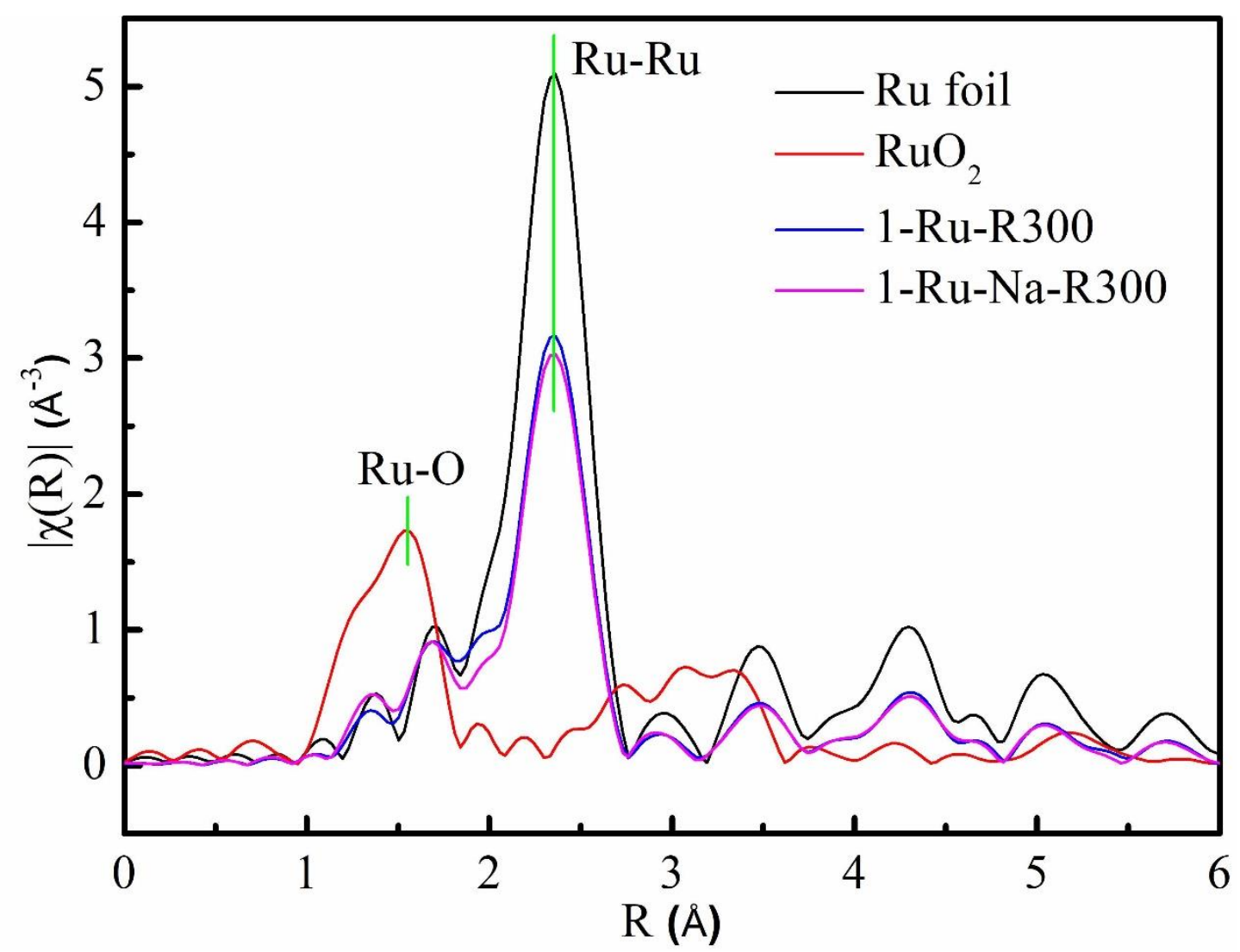

Figure S8. The magnitude of $\mathrm{k}^{2}$-weighted Fourier transforms of the $\mathrm{Ru} \mathrm{K}$-edge EXAFS spectra of 1-Ru-R300 and 1-Ru-Na-R300. 
Table S2. Fitting parameters of the first Ru-Ru and Ru-O shells of Ru k-edge EXAFS with the $\mathrm{Ru}$ foil and $\mathrm{RuO}_{2}$ structures derived from FEFF9. The values of bond distance quoted in the table are corrected for phase shift. Energy shift ( $\left.\mathrm{E}_{0}\right)$ and reduction factor $\left(\mathrm{S}_{0}{ }^{2}\right)$ were set by reference to the standard references. The fit is obtained using k-weighting of 2 in the k range of $1.8 \AA^{-1}<\mathrm{k}<14 \AA^{-1}$.

First Ru-Ru shell

\begin{tabular}{|l|l|l|l|}
\hline Sample & $\mathrm{N}^{\mathrm{a}}$ & $\mathrm{R} / \AA^{\mathrm{b}}$ & $\mathrm{DWF}^{\mathrm{c}}$ \\
\hline Ru foil (model) & 12 & $2.645 \pm 0.005$ & $0.0035 \pm 0.0007$ \\
\hline $1-\mathrm{Ru}-\mathrm{R} 300$ & $9 \pm 0.8$ & $2.677 \pm 0.002$ & $0.0053 \pm 0.0004$ \\
\hline $1-\mathrm{Ru}-\mathrm{Na}-\mathrm{R} 300$ & $8 \pm 0.6$ & $2.672 \pm 0.002$ & $0.0051 \pm 0.0004$ \\
\hline
\end{tabular}

\begin{tabular}{|l|l|l|l|}
\multicolumn{1}{l|}{ First Ru-O shell } & $\mathrm{N}^{\mathrm{a}}$ & $\mathrm{R} / \AA^{\mathrm{b}}$ & $\mathrm{DWF}^{\mathrm{c}}$ \\
\hline Sample & 2 & $1.993 \pm 0.026$ & $0.0047 \pm 0.0017$ \\
\hline $\mathrm{RuO}_{2}$ (model) & $0.3 \pm 0.1$ & $2.063 \pm 0.035$ & $0.0112 \pm 0.0024$ \\
\hline $1-\mathrm{Ru}-\mathrm{R} 300$ & $0.3 \pm 0.1$ & $1.998 \pm 0.025$ & $0.0093 \pm 0.0023$ \\
\hline $1-\mathrm{Ru}-\mathrm{Na}-\mathrm{R} 300$ & & & \\
\hline
\end{tabular}

${ }^{\mathrm{a}} \mathrm{N}=$ average coordination number, ${ }^{\mathrm{b}} \mathrm{R}=$ interatomic distance, ${ }^{\mathrm{c}} \mathrm{DWF}=$ Debye-

Waller Factors, Other parameters: amplitude reduction factor $(\mathrm{amp})=0.87, \mathrm{E}_{0}=-7.2$. 


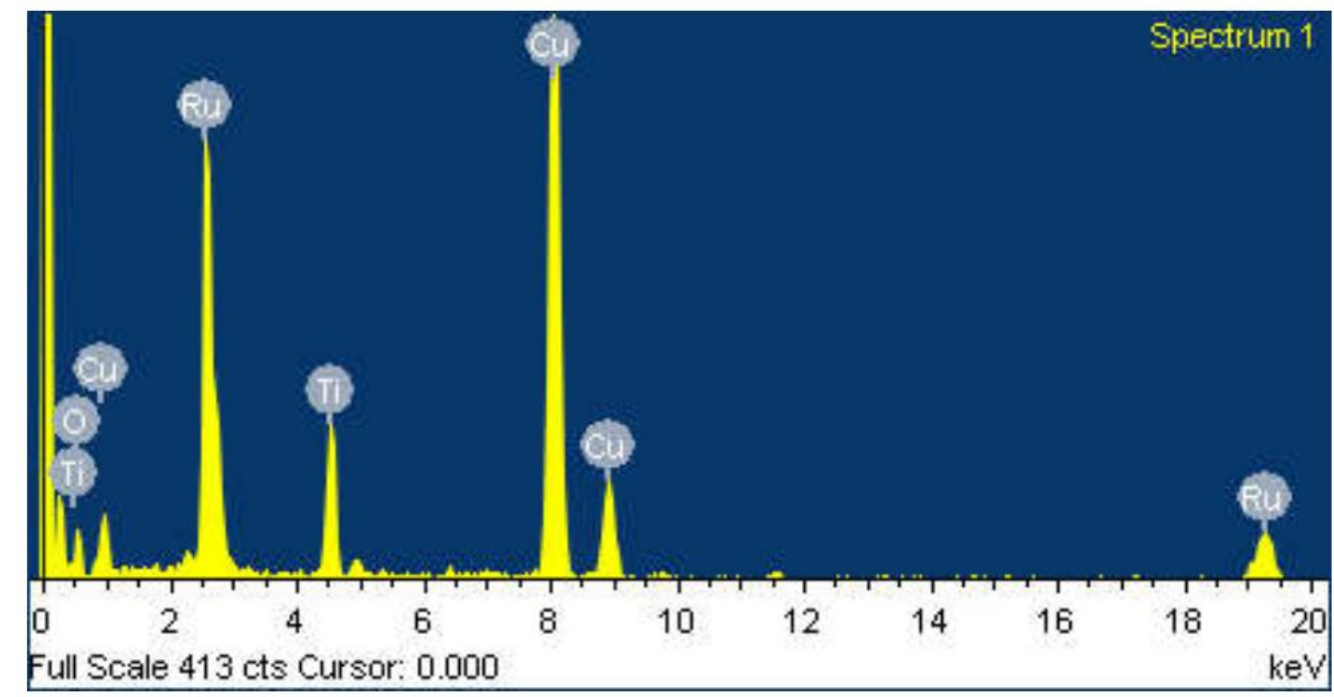

Figure S9. The EDS of the Ru particle of 9-Ru-R300 in Figure 3e.
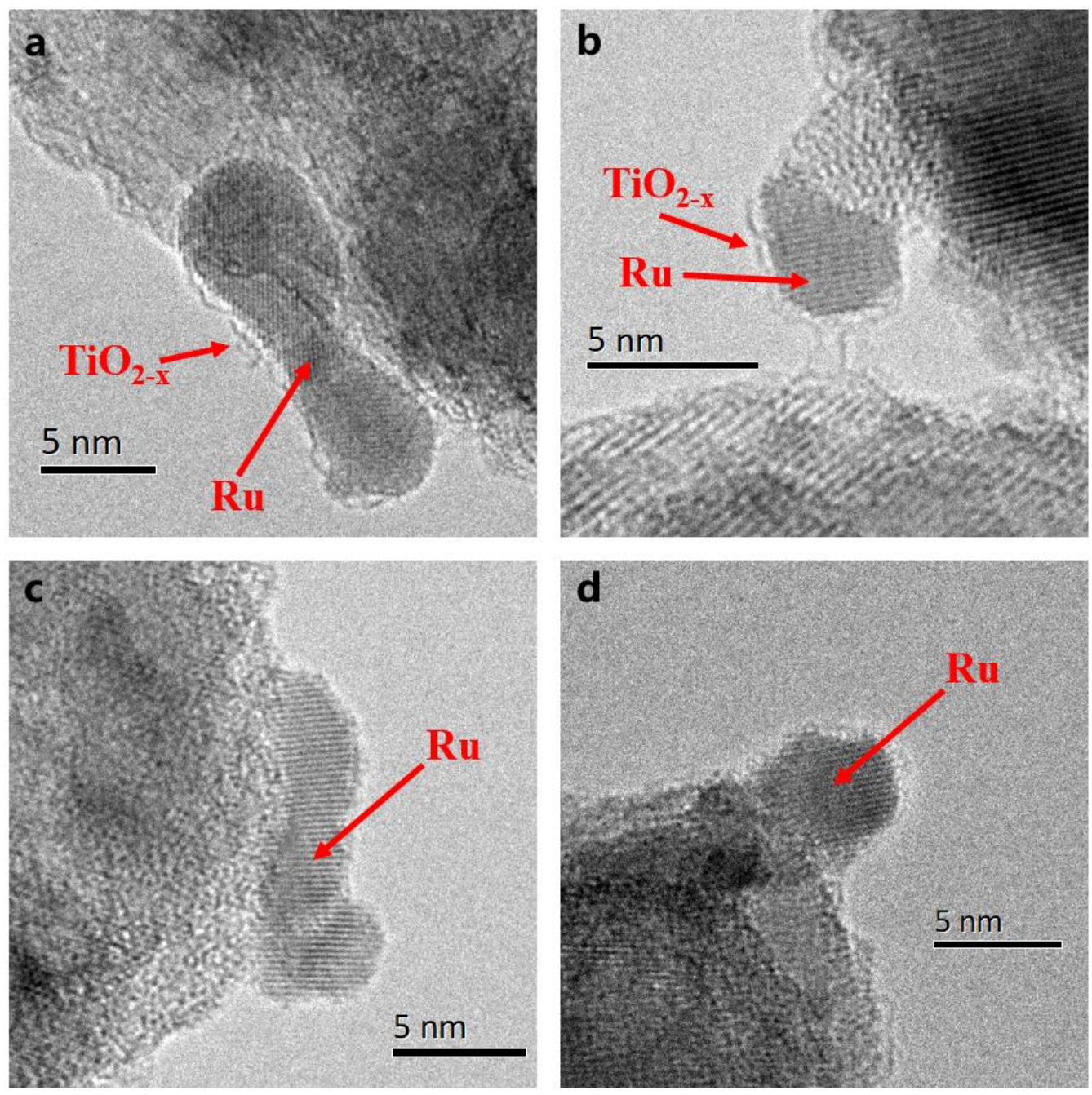

Figure S10. (a) and (b): HRTEM images of 9-Ru-R300; (c) and (d): HRTEM images of 9-Ru-Na-R300. 


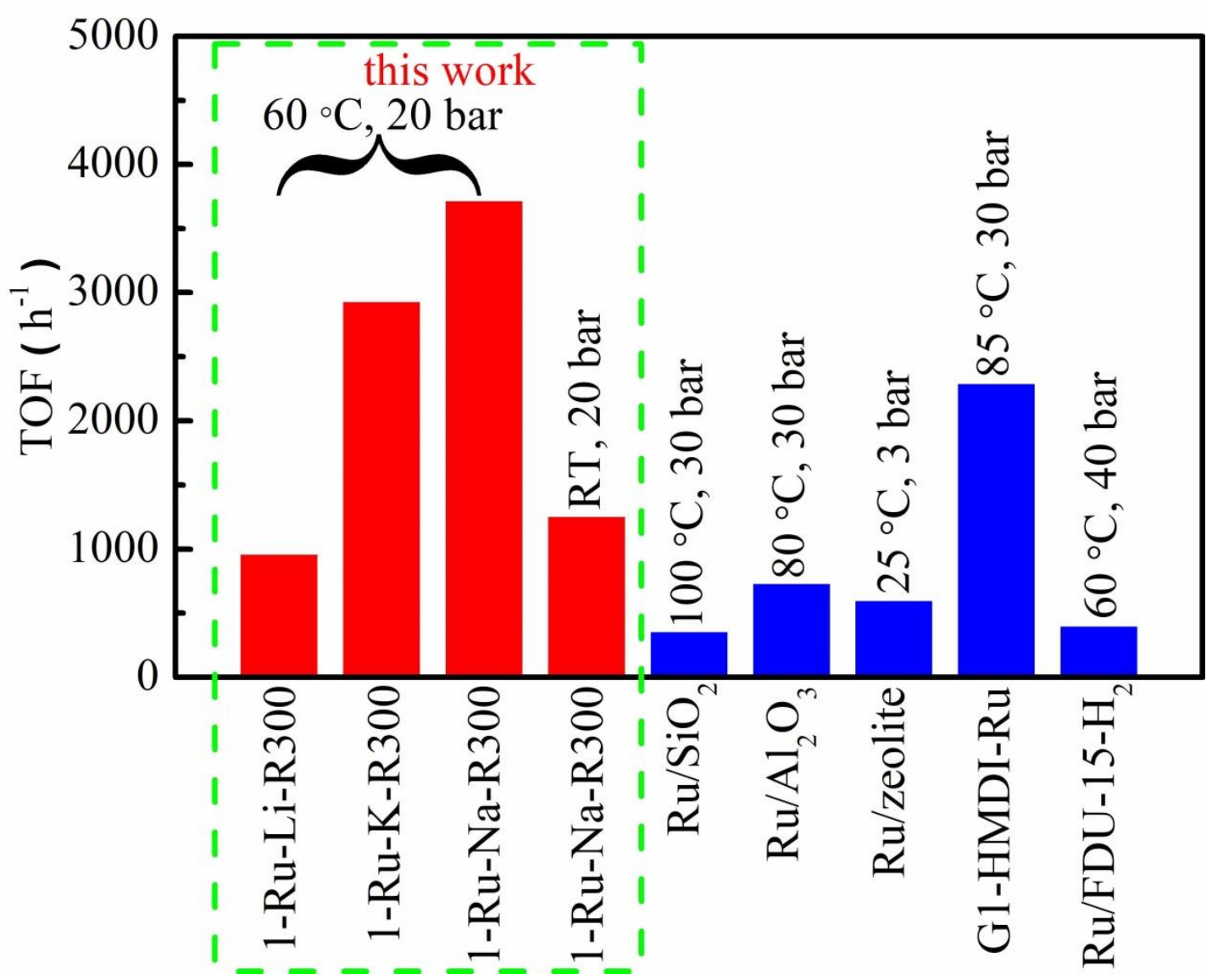

Figure S11. Comparison of TOFs of Ru catalysts for the hydrogenation of toluene in this work (red) with others (blue) in literatures. 


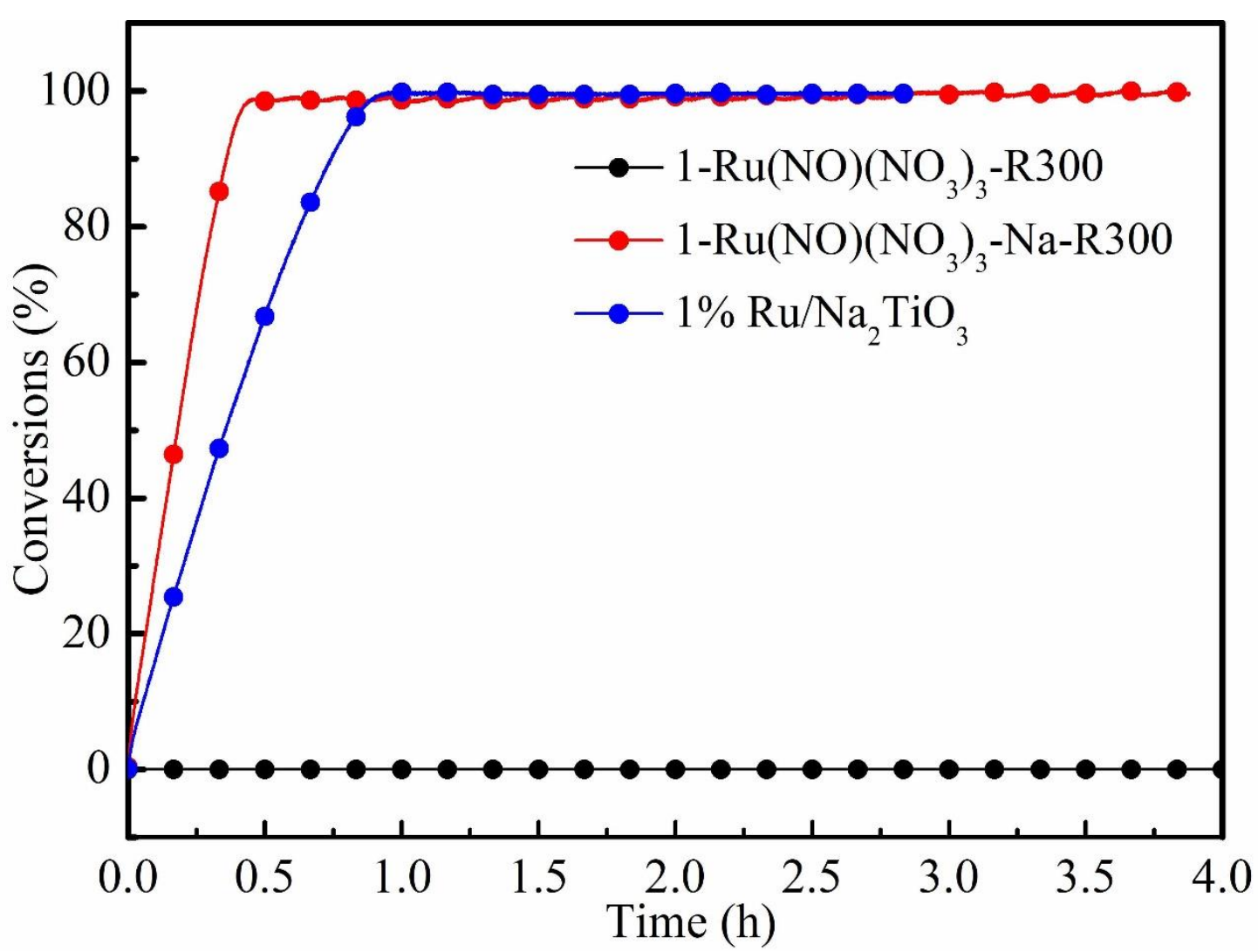

Figure S12. Hydrogenations of toluene at $60{ }^{\circ} \mathrm{C}$ with $1-\mathrm{Ru}(\mathrm{NO})\left(\mathrm{NO}_{3}\right)_{3}-\mathrm{R} 300$, $1-\mathrm{Ru}(\mathrm{NO})\left(\mathrm{NO}_{3}\right)_{3}-\mathrm{Na}-\mathrm{R} 300$ and $1 \% \mathrm{Ru} / \mathrm{Na}_{2} \mathrm{TiO}_{3}$. All the hydrogenations were conducted with $20 \mathrm{mg}$ catalyst, $0.3 \mathrm{~mL}$ toluene dissolved in $20 \mathrm{~mL}$ cyclohexane solvent under 20 bar $\mathrm{H}_{2}$. 


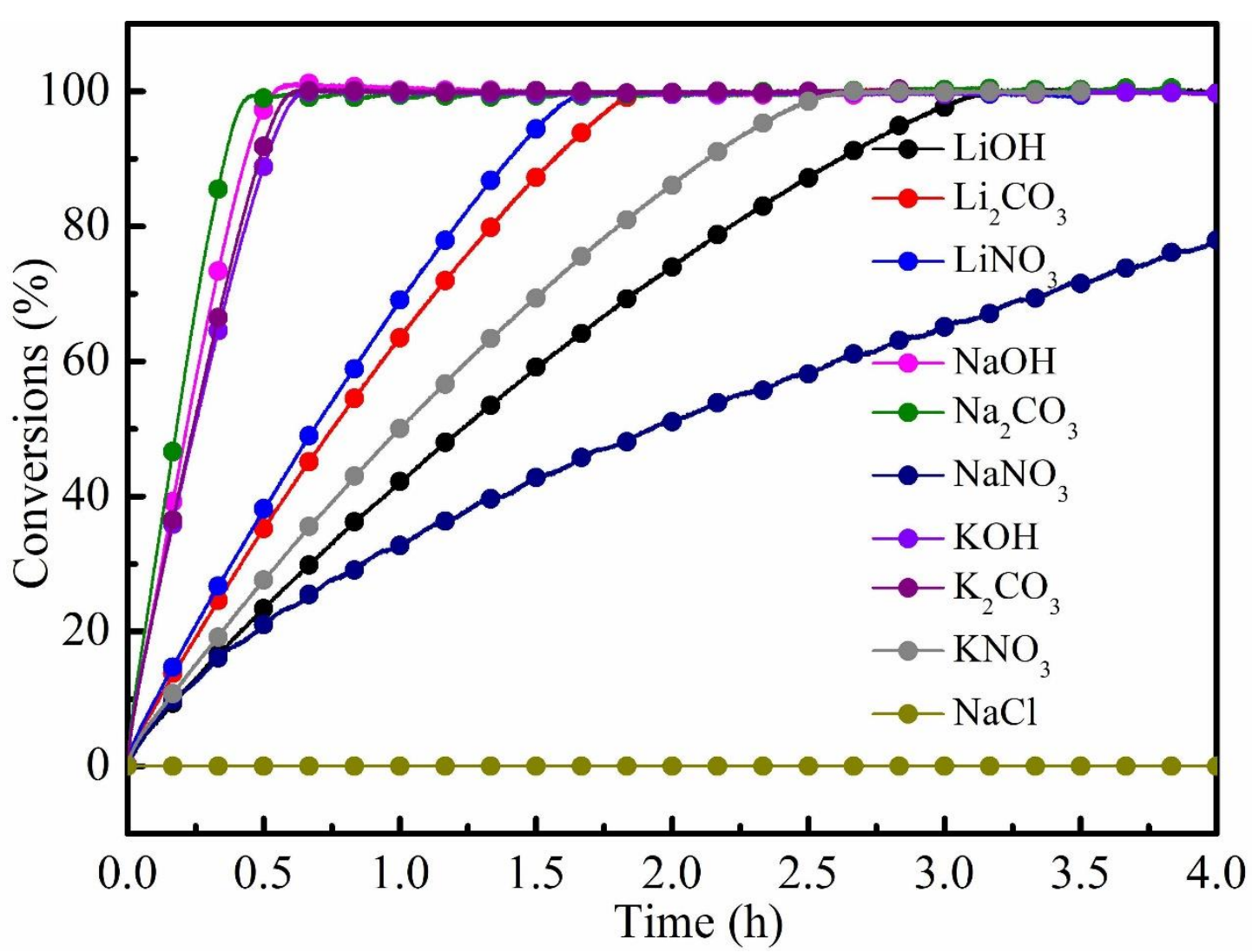

Figure S13. Hydrogenations of toluene at $60{ }^{\circ} \mathrm{C}$ using alkali modified-1\% $\mathrm{Ru} / \mathrm{TiO}_{2}$ catalysts with different alkali salts. All the hydrogenations were conducted with 20 $\mathrm{mg}$ catalyst, $0.3 \mathrm{~mL}$ toluene dissolved in $20 \mathrm{~mL}$ cyclohexane solvent under 20 bar $\mathrm{H}_{2}$. 